\title{
Comparative study of advanced techniques for the diagnosis of induction motors
}

\author{
Abderrrahim Allal ${ }^{1 *}$, Abderrahmane Khechekhouche ${ }^{1.2 *}$, Zied Driss ${ }^{2}$ \\ ${ }^{1}$ Technology faculty, University of El-Oued, Algeria \\ ${ }^{2}$ Laboratory of Electromechanical Systems (LASEM), ENIS, University of Sfax, Tunisia
}

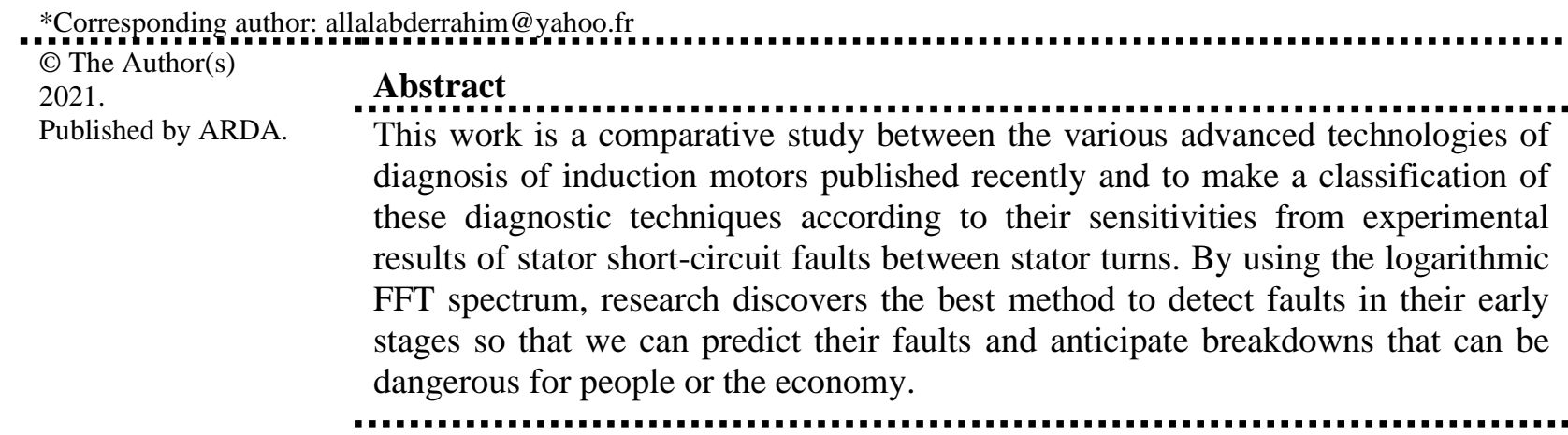

Keywords: Induction motor; Spectral analysis; Stator fault; Diagnosis; Short circuit

\section{Introduction}

The qualities of asynchronous electric motors are that they can sometimes present to the stator and the rotor different types of defects causing premature ageing. The search for signatures or indicators of these faults aims to characterize the operation of the machine by identifying the type and origin of each of the faults; this makes it possible to ensure good discrimination of faults or anomaly occurring at the different levels of the machine [1]. For the detection of the various faults and their diagnosis, it is necessary to know if a fault affects our system by using sensors connected directly in the supply phases and by taking the signals in real time in order to process them and discover the state of our machine [3]. According to specialists in machine diagnostics, it is not only important to detect the fault, but it is also essential to locate it and find its origin [4, 5]. Several methods for diagnosing faults in induction motors are published and proposed by researchers in journals supervised by diagnostic laboratories. They proposed the classical method based on the signature analysis of the motor current of induction motors (MCSA) which is an online diagnostic system with various advanced signal processing algorithms. Over the past decades; much work has been done to find the best diagnostic technique $[6,7]$. Another study proposed a more advanced signal processing method based on the Park-Hilbert "Park-Hilbert" transformation $\left(\mathrm{PVSM}_{\mathrm{P}-\mathrm{H}}\right)$. This group of researchers used "Park vector square modulus" (PVSM) and line current to obtain "motor square current signature analysis" (MSCSA) [8-11]. Researchers have invented the "Park vector product approach (PVPA) for the diagnosis of induction motors" which is based on an improved combination of the Hilbert transform and Park [12-18]. Another very advanced technique called "Hilbert Park vector product approach" (HPVPA) which was inspired by their previous technique. We will carry out a study in order to make a comparison between the various advanced technologies and to make a classification of these diagnostic techniques according to their sensitivities using experimental results of stator short-circuit faults between stator turns. Using the logarithmic FFT spectrum, we can discover the best method to detect faults in their early stages to be able to predict their faults and anticipate breakdowns that can be dangerous on people or the economy. 


\section{Material and methods}

\subsection{Description of the signal extraction tool}

The various faults which affect the MAS will give rise to an influence on the signals coming from this ME by modulating their amplitudes at the characteristic frequencies of these faults. It is necessary to take care with a very satisfactory resolution to make appear clearly the various additional lines the side bands to be able to analyze easily and make the diagnosis of our machine. As an example, we are going to do tests with our experimental bench which has a MAS with two broken bars at full load and then at low load. For this, we will choose a sampling frequency: $\mathrm{Fe}=1000 \mathrm{~Hz}$, an acquisition time of $\mathrm{Ta} \approx 10$ seconds, which implies that the total number of samples $(\mathrm{Ne}=\mathrm{Fe} * \mathrm{Ta})$ : the resolution of our results is therefore equal $\Delta \mathrm{f}=\mathrm{Fe} / \mathrm{Ne}=0.1 \mathrm{~Hz}$.

\subsection{Parameter and operating speed of the motor used}

The motor used in Electrical Engineering Laboratory Biskra University, is three-phase, $3 \mathrm{~kW}, 50 \mathrm{~Hz}, 2$ poles, squirrel cage with 28 bars at the rotor and 360 turns in series per phase as shown in Table 1.

Table 1. Motor Parameters

\begin{tabular}{lll}
\hline Symbols & Parameters & Values \\
\hline$V \mathrm{n}$ & Nominal voltage & $230 / 380 \mathrm{~V}$ \\
\hline $\mathrm{n}$ & Nominal current & $6.40 \mathrm{~A}$ \\
\hline$\omega \mathrm{n}$ & Nominal current & $1430 \mathrm{tr} / \mathrm{min}$ \\
\hline $\mathrm{Nr}$ & Number of rotor bars & 28 \\
\hline$p$ & Number of pole pairs & 2 \\
\hline$f_{\mathrm{s}}$ & Supply frequency & $50 \mathrm{HZ}$ \\
\hline
\end{tabular}

Fig .1 - Fig .10, show the evolution of signatures and their amplitudes and specific frequencies of the different approaches depending on the state of the motor and taking:

1) - Stator fault: - short circuits between 4 turns of a stator winding.

2) - Motor under different operating conditions:

- at low load $(25 \%)$ with slip s $=0.014$.

- at full load (100\%) with slip s $=0.034$.

\section{Results}

To show the sensitivity of the new approaches or methods compared to the other techniques, we made a comparative study between the different approaches in order to know which approach enjoys the best sensitivity. The different techniques are presented in Fig. 1 - Fig. 10.

In order to make a good comparison between these approaches, we must also choose the specific signature frequencies with the greatest amplitude. The frequencies of the characteristic signatures of stator faults are given in Table 1 below:

Table 2. Frequencies characteristic of faults

\begin{tabular}{lc|l}
\hline \multicolumn{1}{c|}{ Approaches } & \multicolumn{1}{l}{$\begin{array}{l}\text { Stator fault } \\
\text { Short circuit between turns }\end{array}$} \\
\hline PVPA & $(2016)$ & $2 f_{s} \pm f_{r \text { a }}$ \\
\hline HPVPA $\quad(2019)$ & $f_{r}$ \\
\hline PVSM - H & $f_{r}$ \\
\hline MSCSA $\quad(2010)$ & $2 f_{s} \pm f_{r \text { a }}$ \\
\hline MCSA & $f_{s} \pm f_{r \text { a }}$ \\
\hline \multicolumn{2}{r}{ a: we take the signature with the greatest amplitude (with + or -) }
\end{tabular}

Fig. 1 and Fig. 2 present the MCSA spectrum to us and allow us to see the specific frequencies of the signatures for each type of defect given in the theoretical part of this present work which confirms the 
correctness of the mathematical equations.

According to Tab. 1 and Fig. 1, the frequency of the MCSA signature whose greatest amplitude is theoretically equal to $f_{s} \pm f_{r}$.

* At low load the slip is worth $g=0.014$, the frequency whose signature is: $f_{c c s}=25.1 \mathrm{~Hz}$

- with 4 short-circuited stator turns: $-65.13 \mathrm{~dB}$.

* At full load, the slip equals $\mathrm{g}=0.034$, the frequency is equal to: $f_{c c s}=9.25 .1 \mathrm{~Hz}$, the frequency found according to Fig. 2:

- with 4 short-circuited stator turns: $-68.99 \mathrm{~dB}$.

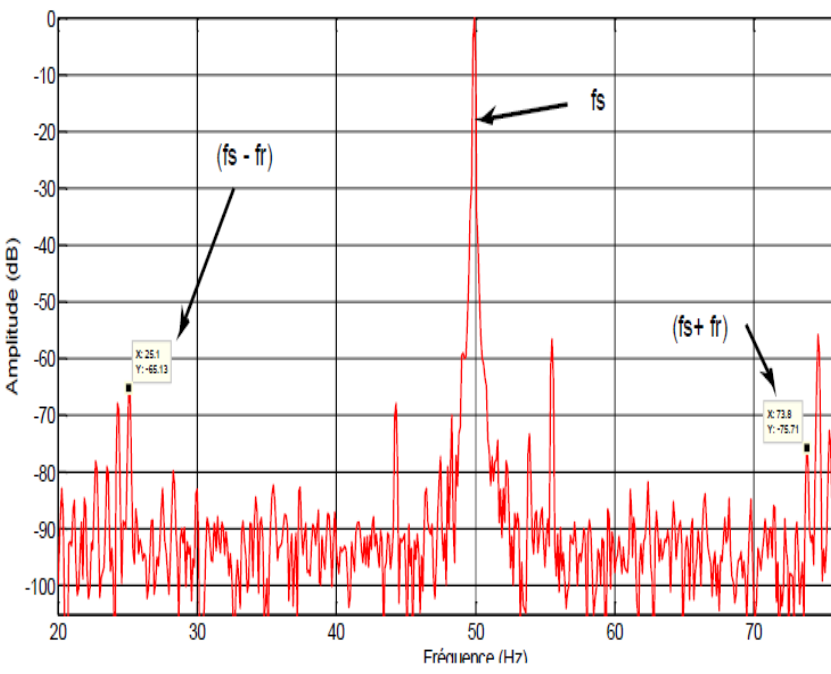

Figure 1. Experimental logarithmic spectrum of the MCSA of a motor with 4 short-circuited stator turns at low load

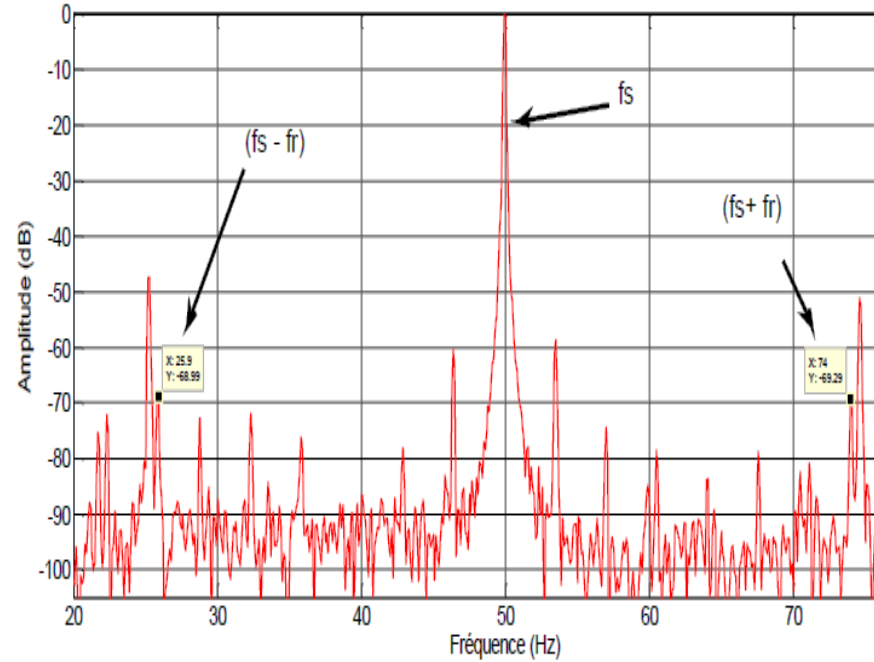

Figure 2. Experimental logarithmic spectrum of the MCSA of a motor with 4 short-circuited stator turns at full load

According to Table 1, Fig. 3, and Fig. 4, the frequency of the signature of MSCSA whose largest amplitude is theoretically equal to $2 f_{s} \pm f_{r}$

* At low load the slip is worth $\mathrm{s}=0.014 \mathrm{~s}$, the theoretical frequency:

$f_{c c s}=124.5 \mathrm{~Hz}$, the analytical simulation frequency according to Fig. 3:

- with 4 short-circuited stator turns: $-56.98 \mathrm{~dB}$.

* At full load the slip is equal to the calculated theoretical frequency: $\mathrm{f} c \mathrm{cs}=75.8 \mathrm{~Hz}$

- with 4 short-circuited stator turns: $-67.49 \mathrm{~dB}$

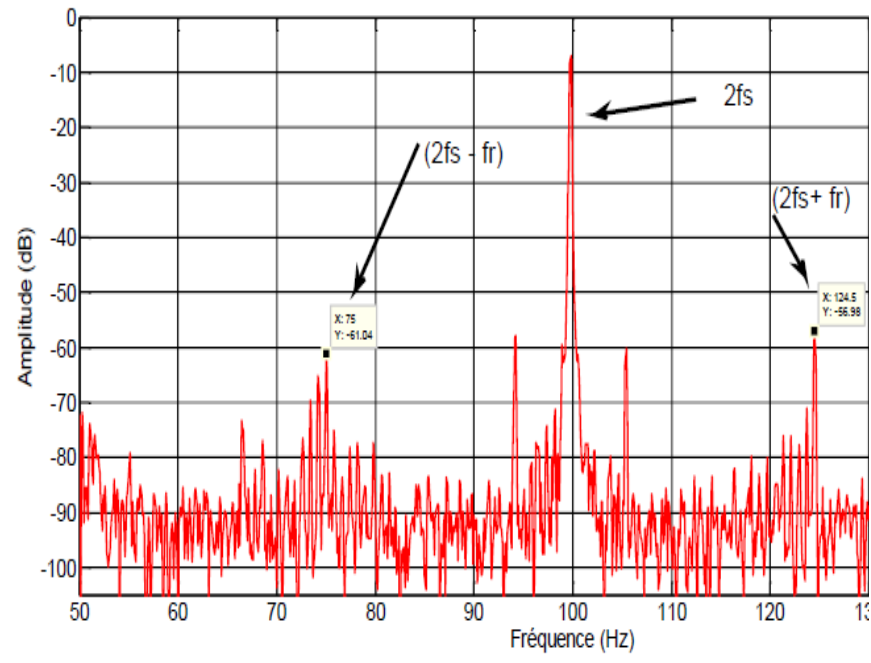

Figure 3. Experimental logarithmic spectrum of the MSCSA of a motor with 4 short-circuited stator turns at low load

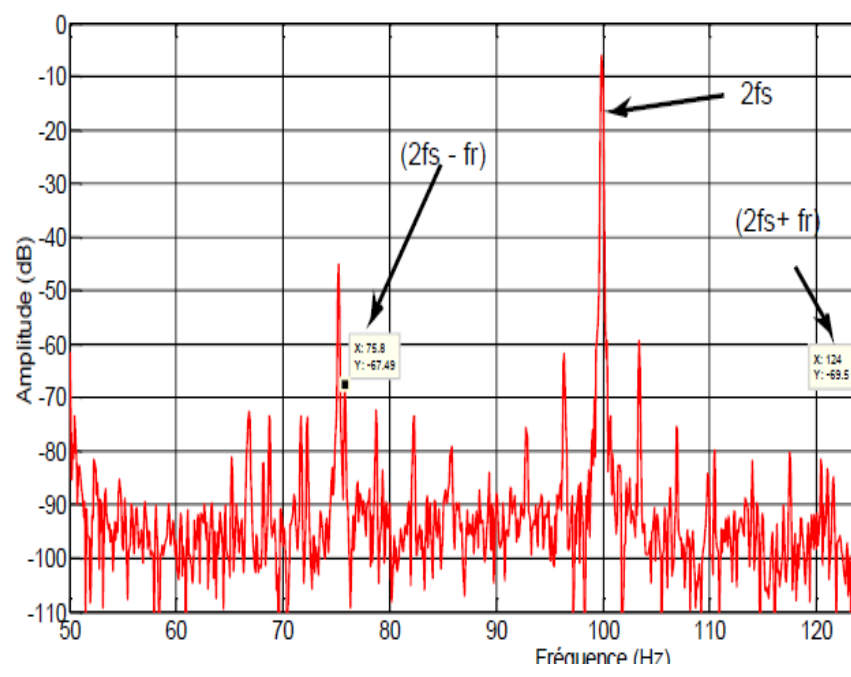

Figure 4. Experimental logarithmic spectrum of the MSCSA of a motor with 4 short-circuited stator turns at full load 
According to Tab. 1 Fig. 5 and Fig. 6, the frequency of the PVPA signature whose greatest amplitude is theoretically equal to $2 f_{s} \pm f_{r}$

* At low load the slip is worth in the healthy state $\mathrm{s}=0.014 \mathrm{~s}$, the theoretically calculated frequency:

Fccs $=124.5 \mathrm{~Hz}$, the analytical frequency of the simulation according to Fig. 5:

- with 4 short-circuited stator turns: $-45.86 \mathrm{~dB}$

* At full load s=0.034 s, the calculated frequency: fccs $=75.8 \mathrm{~Hz}$,

- with 4 short-circuited stator turns: $-60.49 \mathrm{~dB}$

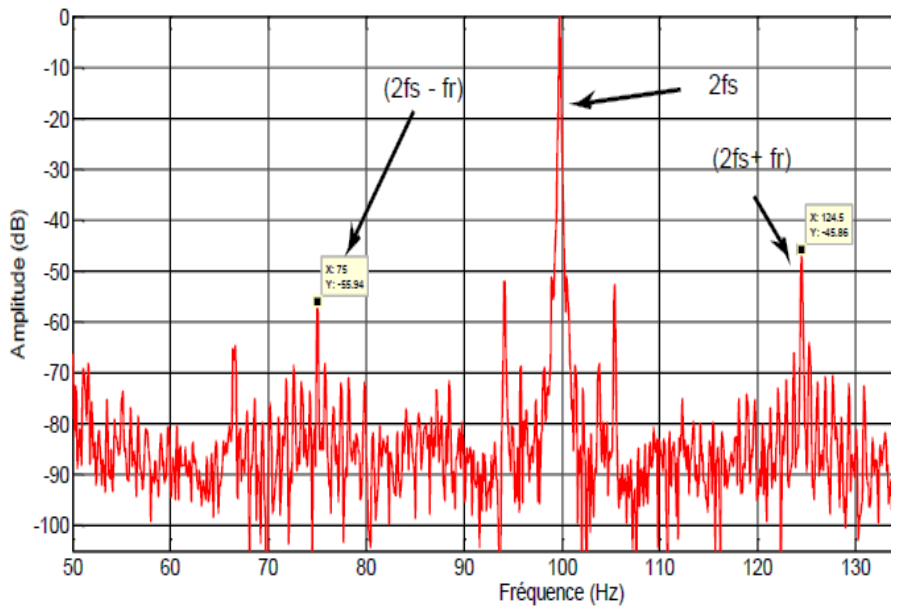

Figure 5. Experimental logarithmic spectrum of PVPA of a motor with 4 short-circuited stator turns at low load

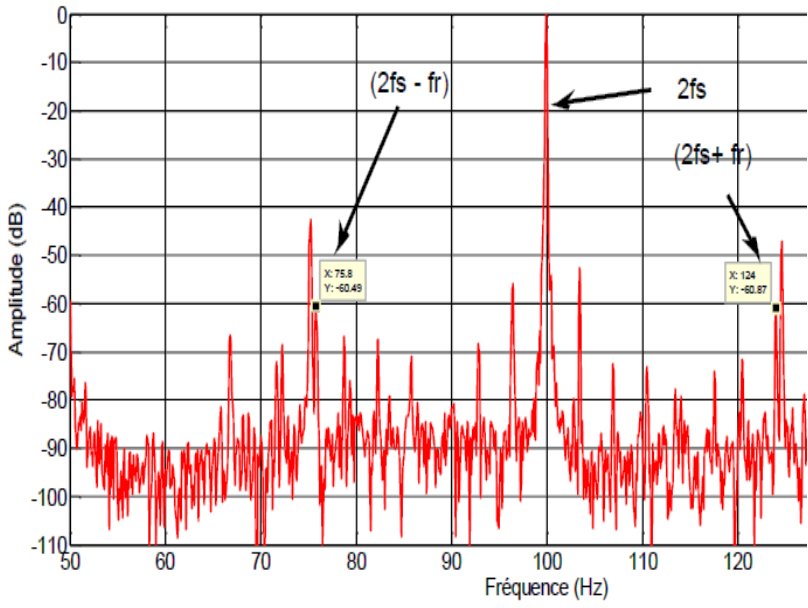

Figure 6. Experimental logarithmic spectrum of PVPA of a motor with 4 short-circuited stator turns at full load

From Tab. 1 Fig. 7 and Fig. 8, the frequency of the signature of PVSM $\mathrm{P}_{-\mathrm{H}}$, the largest amplitude of which is theoretically equal to $f_{r}$ fccs $=24.7 \mathrm{~Hz}$, the analytical simulation frequency according to Fig. 7 :

* At low load $\mathrm{s}=0.04 \mathrm{~s}$, the theoretically calculated frequency:

- with 4 short-circuited stator turns: $-50.65 \mathrm{~dB}$

* At full load s $=0.034 \mathrm{~s}$, the calculated frequency: fccs $=24.7 \mathrm{~Hz}$, the frequency of the simulation according to Fig.8:

- with 4 short-circuited stator turns: $-37.93 \mathrm{~dB}$

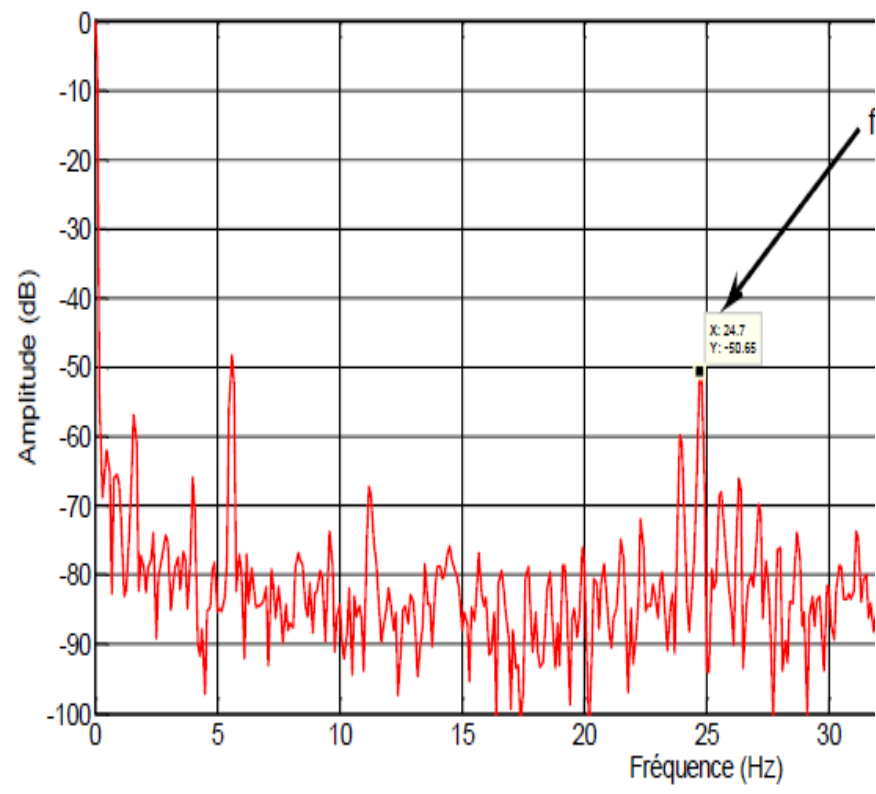

Figure 7. Experimental logarithmic spectrum of the PVSMP $-\mathbf{H}$ of a motor with 4 short-circuited stator turns at low load

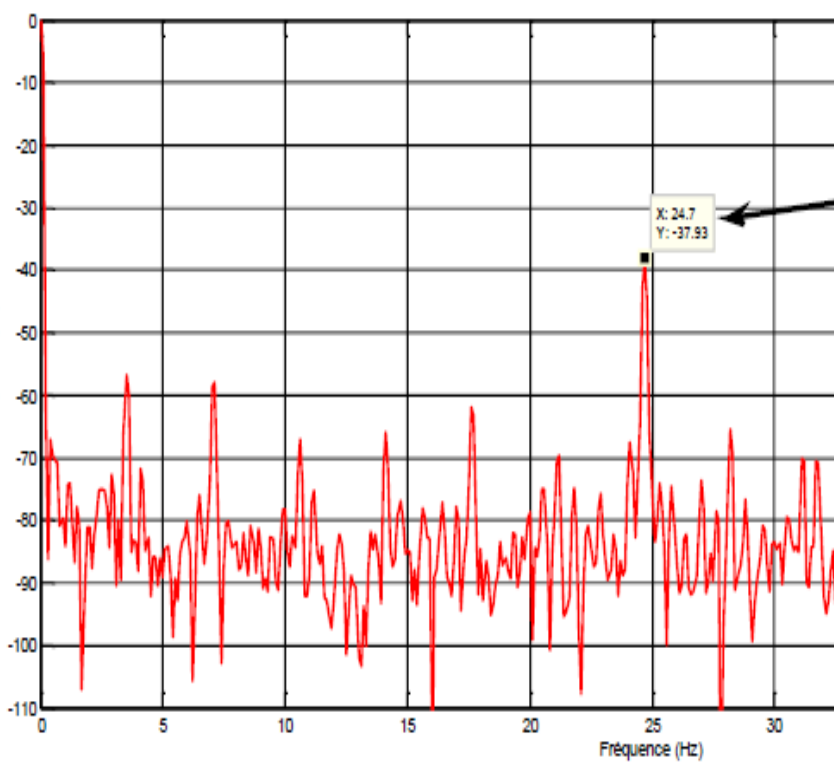

Figure 8. Experimental logarithmic spectrum of the PVSMP $-\mathbf{H}$ of a motor with 4 short-circuited stator turns at full load 
According to Tab.1 Fig. 9 and Fig. 10, the frequency of the signature of HPVPA whose greatest amplitude is theoretically equal to $f r$.

* At low load the slip is worth in the healthy state $\mathrm{s}=0.014$, the calculated theoretical frequency of the signature:

fccs $=24.7 \mathrm{~Hz}$, the calculated theoretical frequency of the signature according to Fig.9.

- with 4 short-circuited stator turns: $-42.26 \mathrm{~dB}$.

* At full load and in the healthy state the slip equals $\mathrm{s}=0.034$, the theoretical frequency:

fccs $=24.7 \mathrm{~Hz}$, the simulation frequency found according to Fig.10:

- with 4 short-circuited stator turns: $-46.01 \mathrm{~dB}$

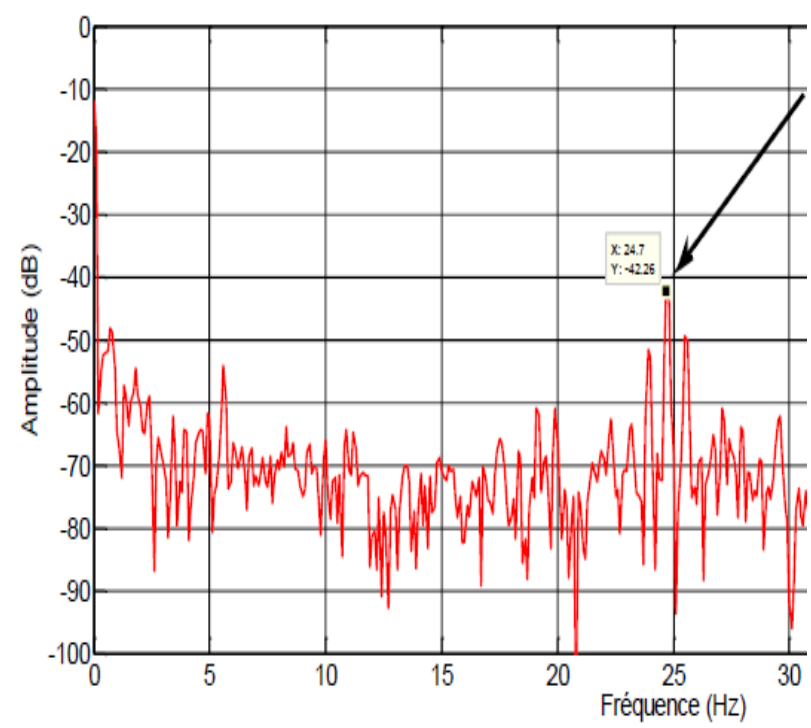

Figure 9. Experimental logarithmic spectrum of the HPVPA of a motor with 4 short-circuited stator turns at low load

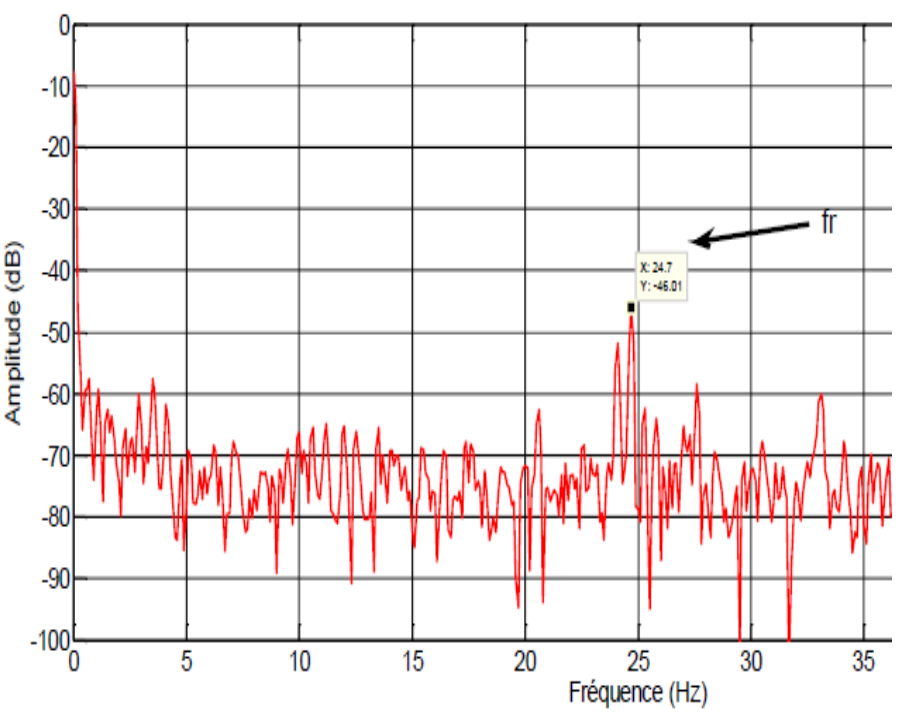

Figure 10. Experimental logarithmic spectrum of the HPVPA of a motor with 4 short-circuited stator turns at full load

\section{Discussion}

After having obtained all the specific signatures of the various approaches to various induction motors defects, choosing the signatures of which the amplitude is the greatest, we draw illustrative graphs which show the sensitivity of each method for each type of fault. Fig.11 clearly show us this work of comparison between these different techniques carried out previously. One can easily notice that the curve of HPVPA is classified

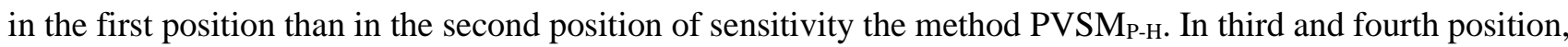
we find successively PVPA then MSCSA. In the last position, we find the classic MCSA method. These results are logical from the history of publications of these techniques in scientific journals.

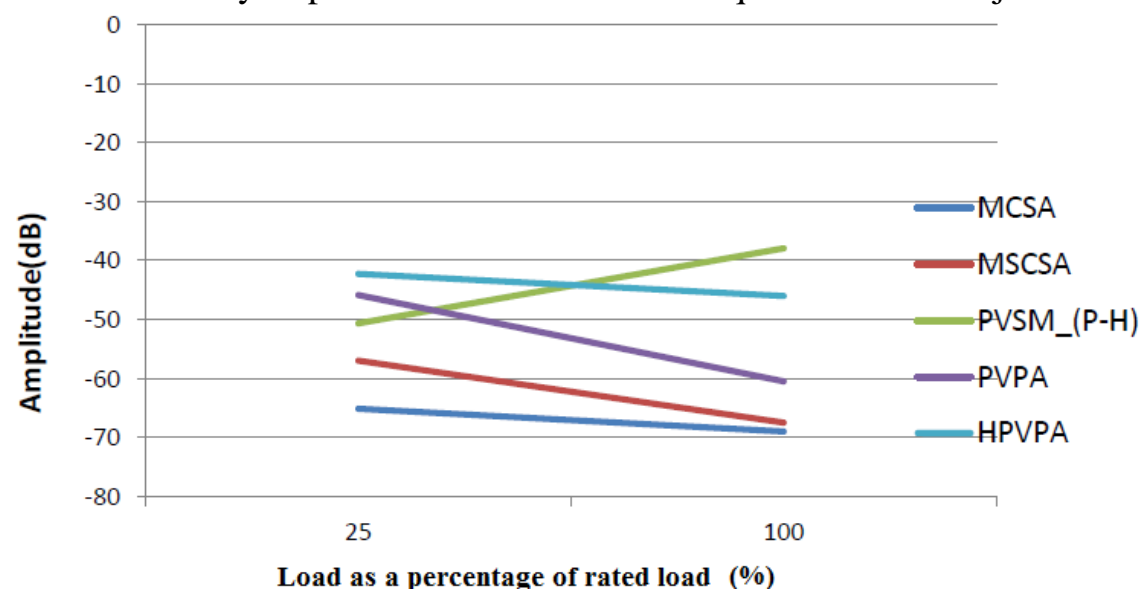

Figure 11. Sensitivity curves of the various advanced diagnostic techniques with 4 short-circuited stator turn 
HSD Vol. 3, No. 1, February 2021, pp.16- 22

Table 1. Classification of diagnostic techniques according to their experimental sensitivities

\begin{tabular}{l|c|c|c}
\hline \multirow{2}{*}{$\begin{array}{l}\text { Techniques } \\
\text { of diagnostic }\end{array}$} & \multicolumn{2}{|l|}{ Stator fault (with 4 short-circuited stator turns) } & $\begin{array}{l}\text { Ranking of advanced } \\
\text { techniques diagnostic }\end{array}$ \\
\cline { 2 - 4 } PVPA & Low load & Full load & $\mathbf{3}$ \\
\hline MSCSA & $\mathbf{2}$ & $\mathbf{3}$ & $\mathbf{4}$ \\
\hline MCSA & $\mathbf{4}$ & $\mathbf{4}$ & $\mathbf{5}$ \\
\hline PVSMP-H & $\mathbf{5}$ & $\mathbf{5}$ & $\mathbf{2}$ \\
\hline HPVPA & $\mathbf{3}$ & $\mathbf{1}$ & $\mathbf{1}$ \\
\hline
\end{tabular}

\section{Conclusion}

After our comparative study between advanced diagnostic techniques (PVPA, MSCSA, MCSA, HPVPA, PVSM $_{\mathrm{P}-\mathrm{H}}$ ) for the diagnosis of stator faults (with 4 short-circuited stator turns) in the two operating states, low load and full load. Thanks to the sensitivity curves of the various advanced diagnostic techniques with 4 shortcircuited stator turn (Experimental results) where we found the HPVPA technique classified at the first position then PVSM P-H $_{\text {H }}$ at the second position, so the methods PVPA then MSCSA have successively the third and then the fourteenth position of sensitivity.

Finally, we have already got our hands on a unique HPVPA method whose sensitivity dominates all other modern techniques, which have been classified, according to their sensitivity, successively PVSM ${ }_{\text {P-H }}$ PVPA, MSCSA and MCSA. Investigations related to induction machine have reported that a large percentage of their faults, which are caused by stator winding faults. Finally, the MCSA method has poor sensitivity for stator faults since it occupies the fifth position.

This comparison allowed us to find the best method of detecting stator faults and which has excellent sensitivity to protect our systems. We can discover the best method to detect faults in their early stages to be able to predict their faults and anticipate breakdowns that can be dangerous on people or on the economy.

\section{References}

[1] M. Blodt, P. Granjon, B. Raison, G. Rostaing," "Models for bearing damage detection in induction motors using stator current monitoring", IEEE Trans. Ind. Electron.,vol. 55, no. 4, pp. 1813- 1822, 2008.

[2] M. Boucherma, M. Y. Kaikaa ,A. Khezzar , Park model of squirrel cage induction machine including space harmonics effect, Journal of Electrical Engineering, vo 1 57, No.4, pp. 193-199, 2006.

[3] E. Lughofer, E. P. Klement, "Model-based fault detection in multi-sensor measurement systems, Technical report Fll1/Tr/0303", Johannes Kepler University Linz, Austria.

[4] S. Ben Salem, K. Bacha, A. Chaari, "Support vector machine-based decision for induction motor fault diagnosis using air-gap torque frequency response", International Journal of Computer Applications, vol 38, no.5, pp. 27-33, 2012.

[5] S. Ben Salem, K. Bacha, A. Chaari, "Support vector machine based decision for mechanical fault condition monitoring in induction motor using an advanced Hilbert-Park transform", ISA Trans., vol. 51, no.5, pp. 566-572, 2012.

[6] T. Sribovornmongkol, "Evaluation of motor online diagnosis by FEM simulations", Thesis, Royal Institute of Technology Stockholm, Sweden, 2006.

[7] K. Bacha, S. Ben Salem, A. Chaari, "An improved combination of Hilbert and Park transforms for fault detection and identification in three-phase induction motors", Electrical Power and Energy Systems, vol 43, no.1, pp.1006-1016, 2012.

[8] Mohamed Sahraoui, Adel Ghoggal, Salim Guedidi, Salah Eddine Zouzou, "Detection of inter-turn shortcircuit in induction motors using Park-Hilbert method", International Journal of System Assurance Engineering and Management, vol 5, no.3, pp. 337-351, 2014.

[9] M. Sahraoui, "Etude comparative des méthodes de diagnostic des machines asynchrones (Comparative study of the methods of diagnosis in the asynchronous machines)", Thesis for the degree of Doctor of Science, Biskra university, Algeria, 2010. 
[10] V. F. Pires, M. Kadivonga, J. F. Martins, A.J. Pires, "Motor square current signature analysis for induction motor rotor diagnosis", Measurement, vol. 46, no.2, pp. 942-948, 2013.

[11] A. Allal, B. Chetate, "High sensitivity detection of the stator short-circuit faultsin induction motor using Hilbert Park's vector product”, J. Fundam. Appl. Sci., vol. 11, no. 2, pp. 994-1022, 2019.

[12] M. Sahraoui, S. E. Zouzou, A. Ghoggal, S. Guedidi, "A new method to detect inter-turn shortcircuit in induction motors, $19^{\text {nd }}$ ed., International conference on Electrical Machine (ICEM,2010 -Rome, Italy), IEEE, pp. 1-6, 2010.

[13] S. E. Zouzou. , M. Sahraoui, A. Ghoggal, et al. "Detection of inter- turn short-circuit and broken rotor bars in induction motors using the partial relative indexes: application on the MCSA," 19nd ed., International conference on Electrical Machine (ICEM,2010), Sept 2010, (Rome,Italy), IEEE, p 1-6, 2010.

[14] A. Allal , B. Chetate, D. Benattous, "The Instantaneous Power Approach for Rotor Cage Fault Diagnosis in Induction Motor," 6 th symposium on Hydrocarbons and chemistry ISHC6, (Zeralda, Algiers), 2012.

[15] I. Chouidira, K. Djalal Eddine, H. Benguesmia,Detection and Diagnosis faults in Machine asynchronous based on single processing," International Journal of Energetica (IJECA), vol. 4, no. 1, pp. 11-16, 2019.

[16] A. Allal, B. Chetate, "A new and best approach for early detection of rotor and stator faults in induction motors coupled to variable loads", Frontiers in Energy, vol. 10, no. 2, pp. 176-191, 2016.

[17] A. Allal, "Nouvelles méthodes et techniques de diagnostic des machines asynchrones à rotor en cage d'écureuil (New methods and diagnostic techniques asynchronous machines of squirrel cage rotor)," Thesis for the degree of Doctor of Science, Boumerdes university, Algeria, 2017.

[18] Abderrrahim Allal, Abderrahmane Khechekhouche, Zied Driss, "Induction machines diagnosis by the time's harmonics", International Journal of Energetica, vol. 5, no. 2, pp. 32-36, 2020. 